ROBERT KOCH INSTITUT

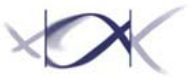

Originally published as:

Schlaud, M.

The death-scene investigation

(2010) Current Pediatric Reviews, 6 (1), pp. 27-29.

DOI: $10.2174 / 157339610791317142$

The definitive version is available at: http://www.bentham.org/cpr/ 


\section{The death-scene investigation}

Martin Schlaud

Affiliation:

Robert Koch Institute; Berlin, Germany.

\section{Correspondence to:}

Martin Schlaud

Robert Koch Institute, Dept. of Epidemiology and Health Reporting

PO Box 6502 61,

13302 Berlin, Germany

Telephone: (+49) 3018 754-3437

Telefax: (+49) 3018 10-754-3437

E-Mail: m.schlaud@rki.de 


\begin{abstract}
The death-scene investigation is an important and increasingly recognized step in the process of diagnosing Sudden Infant Death Syndrome (SIDS). According to current definitions, information from death-scene investigations is required when SIDS diagnoses are made. Due to differences in national jurisdictions, however, there are differences in the methods used and the professions involved in routinely performed death-scene investigations. Therefore any international comparability of death-scene data is limited.
\end{abstract}

Only a few epidemiological studies have used thorough death-scene investigations in a systematic way, including a standardized, objective observation of the scene in cases and reference data from the general population. These studies gave close insights into the circumstances of infant death, but their complex protocols are mostly not feasible for routine use. For that purpose, manageable death scene investigation protocols need to be distilled from the ones used in complex studies, taking into account their results.

Whilst protocols for post-mortem examinations and definitions for SIDS have been largely standardized and agreed internationally, this step is still missing for death-scene investigations. If routinely obtained death-scene data were standardized and, thus, comparable, this would have a potential of generating new hypotheses that eventually lead to a better understanding of the underlying mechanisms and to more effective measures of prevention. 


\section{INTRODUCTION}

Even from ancient times, there are reports of sudden and unexpected deaths in infancy or early childhood. First written notes which may possibly be linked to Sudden Infant Death Syndrome (SIDS) can be found in the Bible. After the exodus of the Israelites from Egypt, seven plagues were sent upon them. The seventh and worst was the death of all firstborn children. Elsewhere in the Bible, there are reports of mothers overlaying their infants and smothering them to death. Several centuries later, some medieval decrees addressed this overlaying with the Latin term “oppression infantum”. [1]

In the 17th to 19th century, first attempts were made to explain sudden infant death as a consequence from certain medical conditions. There were hypotheses that an enlarged thymus may have caused suffocation in dead infants, a supposed condition named "asthma thymicum” which was later regarded as a sign of a complex developmental disorder of "lymphatic-chlorotic nature”. [2] In consequence of these hypotheses, the thymus of infants got routinely radiated by $\mathrm{x}$-ray as a prophylactic measure in the early 20th century. [3]

With the gradual decline in infant mortality in the 1950s and 1960s, cases of sudden infant death became more visible and more important. With increasing awareness of this apparently new problem, a conference was convened in Seattle, WA, in 1969 and the first serious definition of SIDS was proposed by a panel of experts:

“The sudden death of any infant or young child which is unexpected by history, and in which a thorough post-mortem examination fails to demonstrate an adequate cause of death.“ [4] 
Although is soon became evident that most SIDS cases occurred during sleep, the death scene, which may reveal important information about the sleep environment and circumstances of deaths, was not considered important at that time. Some twenty years later, however, the perception had grown that it is vital to study the death scene very thoroughly before SIDS can be diagnosed by exclusion with some certainty. A new, extended definition of SIDS was proposed:

“The sudden death of an infant under one year of age which remains unexplained after a thorough case investigation, including performance of a complete autopsy, examination of the death scene, and a review of the clinical history. “ [5]

A systematic investigation of the death scene not only turned out to reveal important information of the circumstances of death and helped understand the findings of post-mortem examinations. Moreover, potentially dangerous sleeping environments [6, 7] and, in particular, various risk factors for SIDS could be identified. Most importantly, the prone sleeping position [8], but also overheating by clothing or heating devices [9], soft mattresses [10], and bedding material [11] were found to be associated with SIDS. There are still some controversies about the potential risk of co-sleeping $[12,13]$ and the potentially protective effect of pacifier use on risk of SIDS. [14] All these factors are present in the sleep environment and could be identified by research into the scene of death.

In 2004, Krous et al. made certain findings from death scene investigations, e.g. a safe sleep environment, part of their proposed definitions of categories of SIDS, which incorporated degrees of diagnostic certainty. [15] This demonstrates the remarkable increase in the recognized importance of death-scene information in the context of SIDS over 35 years of research. 


\section{DEATH SCENE INVESTIGATIONS IN SIDS STUDIES}

Though data on the circumstances of death and the death scene after finding a dead baby have been obtained in scientific studies for a long time in many epidemiological studies, only a few have used thorough death-scene investigations in a systematic way, including a standardized, objective observation of the scene in cases and reference data from the general population. Making standardized scene investigations in cases only $[7,16]$ is a valuable first step, but results may be difficult to interpret when reference data from living controls are missing. Allegedly striking findings in cases may turn out meaningless when they do not differ from findings in living controls. Even when using reference data from case-control studies [17], results from retrospective interviews of parents may be substantially affected by recall bias. Rather than obtaining death-scene data by parent interviews alone, letting parents reenact the death scene with the use of baby-like dolls [7] turned out to be a more realistic, intuitive and enlightening method, although still retrospective and prone to recall bias.

Ideally, studies into the death scene and sleep environment should be done by standardized observation, timed as closely to the fatal event as possible so the dead baby is still where it was found, and with living control infants as a reference. Beyond the static scene found, data on the circumstances should be obtained by standardized parent interview. This includes questions on the time the baby was last fed, brought to sleep or heard, on any unusual occurrences, and on what has changed after the case was found. Visits to control parents should be appointed at short notice, so the place is in the usual condition and not tidied up for the visitor. Control infants should be at the same age and the time of the day the same as when the respective case was found dead. 
The first study that included all these elements was conducted in Germany from 19982002 [18]. A similar study was undertaken in England from 2003-2006 [19]. Both studies turned out to be extremely complex in both logistics and data analysis, but gave close insights into the circumstances of infant death. The analyses of the enormous amount of data gathered during both studies are still ongoing. 


\section{CURRENT PRACTICE OF ROUTINE SCENE INVESTIGATION - OP- PORTUNITIES AND LIMITATIONS}

To what extent death-scene investigations are carried out on a routine basis after an infant was found dead varies considerably from country to country, according to the respective legislation. In most countries, any sudden unexplained infant death (SUID) will give rise to an investigation by the police or other authorities, and a scene investigation usually is an important part of this. The primary aim of this sort of investigation is to clarify whether the death had natural or unnatural causes. Unnatural causes include accidents, abuse, neglect and infanticide. The consequences of the investigations may be penalization of any perpetrator and/or prevention of further fatalities by eliminating any hazardous factors, e.g. so far unrecognized causes of accidents.

To a much lesser extent are the findings of scene investigations used to clarify the underlying cause of death. Although part of current definitions of SIDS, findings from scene investigations are not necessarily incorporated in the final diagnosis of the underlying cause of death. This practice varies considerably between countries and sometimes even between regions or states in the same country. Also missing is a systematic scientific evaluation of findings made in routine scene investigations, although this may be an important source of new scientific evidence. If routinely obtained death-scene data could be analyzed in scientific studies, this would have a potential of generating new hypotheses that needed to be confirmed in epidemiological studies and eventually lead to more effective measures of prevention.

One of the reasons why this is not usually the case is that death-scene investigations in sudden unexpected infant deaths (SUDI) are not generally standardized. There may or may not be protocols in place on a national level, but even if they exist, an international standardi- 
zation is still missing. A step in the right direction was done by the CDC in 1996 when guidelines and recommendations were issued for the US. [20, 21]. However, not even in the US is the use of these guidelines and forms mandated and a subsequent survey revealed that they were not widely used. [22] Acceptance in the US may be better with revised forms and recommendations, but even if successful in the US, an international standardization of deathscene protocols is still missing and will be hard to achieve. Protocols for post-mortem examinations [23] and definitions for SIDS [24] could - at least in part - be standardized on an international level. However, this step is still missing for death-scene investigations, both for methods and interpretation of findings, and remains a major challenge for the future. 


\section{CONCLUSIONS}

The death-scene investigation is an important step in the process of diagnosing SIDS. According to current definitions of SIDS, information from death-scene investigations is required when SIDS diagnoses are made. Due to differences in national jurisdictions, however, there are differences in the methods used and the professions involved. Therefore any international comparability of death-scene information is limited.

The complex protocols used in epidemiological studies investigating the death scene of SIDS cases are mostly not feasible for routine use. For that purpose, manageable death scene investigation protocols need to be distilled from the ones used in complex studies, taking into account their results. The protocols also need to consider reference information from living controls, stratified by cultural, ethic and socio-economic background. Protocols for routine use should obtain fewer and the most meaningful indicators from the death scene in a standardized way. The CDC guidelines, which have been used, evaluated and further developed in the US since 1996, are a good starting point for internationally agreed protocols for routine use.

If procedures to diagnose SIDS from all available information, including death-scene data, could be internationally standardized, this would give opportunities to better compare SIDS mortality rates between countries and to better understand the complex mechanisms eventually leading to sudden death in infancy. Hopefully, more individualized and, thus, more effective measures of prevention could be developed and introduced, further reducing the risk of SIDS and the fears of parents. 


\section{References}

1. Arnold K: Kindstötung und Kindersterblichkeit. In: Lexikon des Mittelalters. Edited by Bautier R-H, M. BH, vol. 5. Munich: Artemis 1991.

2. Palthauf A: Über die Beziehung des Thymus zum Plötzlichen Tod. Wien Med Wochenschr 1889, 2:877-881.

3. Franciosi RA: Evolution of SIDS diagnosis. Minn Med 1983, 66:411-417.

4. Bergmann AB, Beckwith JB, Ray CG: Sudden infant death syndrome. Conference, September 1969. Seattle: University of Washington Press; 1970.

5. Willinger M, James LS, Catz C: Defining the sudden infant death syndrome (SIDS): deliberations of an expert panel convened by the National Institute of Child Health and Human Development. Pediatr Pathol 1991, 11(5):677-684.

6. Byard RW, Beal S, Bourne AJ: Potentially dangerous sleeping environments and accidental asphyxia in infancy and early childhood. Arch Dis Child 1994, 71(6):497500 .

7. Kemp JS, Unger B, Wilkins D, Psara RM, Ledbetter TL, Graham MA, Case M, Thach BT: Unsafe sleep practices and an analysis of bedsharing among infants dying suddenly and unexpectedly: results of a four-year, population-based, death-scene investigation study of sudden infant death syndrome and related deaths. Pediatrics 2000, 106(3):E41.

8. Beal SM, Finch CF: An overview of retrospective case-control studies investigating the relationship between prone sleeping position and SIDS. J Paediatr Child Health 1991, 27(6):334-339.

9. Guntheroth WG, Spiers PS: Thermal stress in sudden infant death: is there an ambiguity with the rebreathing hypothesis? Pediatrics 2001, 107(4):693-698.

10. Mitchell EA, Scragg L, Clements M: Soft cot mattresses and the sudden infant death syndrome. N Z Med J 1996, 109(1023):206-207. 
11. Mitchell EA, Williams SM, Taylor BJ: Use of duvets and the risk of sudden infant death syndrome. ArchDisChild 1999, 81(2):117-119.

12. Blair PS: Putting co-sleeping into perspective. J Pediatr (Rio J) 2008, 84(2):99-101.

13. Thoman EB: Co-sleeping, an ancient practice: issues of the past and present, and possibilities for the future. Sleep Med Rev 2006, 10(6):407-417.

14. Hauck FR, Omojokun OO, Siadaty MS: Do pacifiers reduce the risk of sudden infant death syndrome? A meta-analysis. Pediatrics 2005, 116(5):e716-e723.

15. Krous HF, Beckwith JB, Byard RW, Rognum TO, Bajanowski T, Corey T, Cutz E, Hanzlick R, Keens TG, Mitchell EA: Sudden infant death syndrome and unclassified sudden infant deaths: a definitional and diagnostic approach. Pediatrics 2004, 114(1):234-238.

16. Bass M, Kravath RE, Glass L: Death-scene investigation in sudden infant death. $N$ EnglJ Med 1986, 315:100-105.

17. Klonoff-Cohen HS, Edelstein SL: A case-control study of routine and death scene sleep position and sudden infant death syndrome in Southern California. JAMA 1995, 273(10):790-794.

18. Schlaud M, Dreier M, Debertin AS, Jachau K, Heide S, Giebe B, Sperhake JP, Poets CF, Kleemann WJ: The German case-control scene investigation study on SIDS: epidemiological approach and main results. Int J Legal Med 2010, 124(1):19-26.

19. Blair PS, Sidebotham P, Evason-Coombe C, Edmonds M, Heckstall-Smith EM, Fleming P: Hazardous cosleeping environments and risk factors amenable to change: case-control study of SIDS in south west England. BMJ 2009, 339:b3666.

20. Prevention CfDCa: Guidelines for death scene investigation of sudden, unexplained infant deaths: recommendations of the Interagency Panel on Sudden Infant Death Syndrome. MMWR Morb Mortal Wkly Rep 1996, 45(RR-10):1-22. 
21. Iyasu S, Rowley DL, Hanzlik L, Willinger M: Guidelines for death scene investigation of sudden, unexplained infant deaths: recommendations of the interagency panel on sudden infant death syndrome. J SIDS Infant Mortal 1996, 1:183-202.

22. Hauck F: Final Report: National Survey to Evaluate Use of the Sudden Unexplained Infant Death Investigation Report Form (SUIDIRF). Charlottesville, VA: University of Virginia Health System; 2001.

23. Brinkmann B: Harmonization of medico-legal autopsy rules. Committee of Ministers. Council of Europe. IntJ Legal Med 1999, 113(1):1-14.

24. Bajanowski T, Vege A, Byard RW, Krous HF, Arnestad M, Bachs L, Banner J, Blair PS, Borthne A, Dettmeyer R et al: Sudden infant death syndrome (SIDS)--standardised investigations and classification: recommendations. Forensic Sci Int 2007, 165(23):129-143. 